\title{
GENOTYPING OF VARICELLA-ZOSTER VIRUS (VZV) WILD-TYPE STRAINS ISOLATED IN THE CZECH REPUBLIC
}

\author{
Vanda Bostikova ${ }^{\mathrm{a}}$, Miloslav Salavec ${ }^{\mathrm{b}}$, Jan Smetana ${ }^{\mathrm{a}}$, Roman Chlibek ${ }^{\mathrm{a}}$, Pavel Kosina ${ }^{\mathrm{c}}$, \\ Petr Prasil ${ }^{c}$, Stanislav Plisek ${ }^{\mathrm{c}}$, Miroslav Splino ${ }^{\mathrm{a}}$, Pavel Bostik ${ }^{\mathrm{a}, \mathrm{c}}$ \\ ${ }^{a}$ Faculty of Military Health Sciences, University of Defence, Hradec Kralove, Czech Republic \\ ${ }^{b}$ Department of Dermatology, Charles University Medical School and University Hospital, Hradec Kralove \\ c Department of Infectious Diseases, Charles University Medical School and University Hospital, Hradec Kralove \\ E-mail:smetana@pmfhk.cz
}

Received: May 12, 2011; Accepted with revision: October 20, 2011; Available online: November 30, 2011

Key words: Varicella-zoster virus/Wild-type/open reading frame/Genotyping/Czech Republic/Single nucleotide polymorphism

Objectives. Monitoring of the varicella-zoster virus is becoming an important tool for analysis of the circulation of individual strains of VZV which differ not only at the genomic level, but show a variability in their clinical and epidemiological characteristics. Such data are not available on a large scale from the Czech population and could help understanding the epidemiological and evolutionary characteristics of the virus, as well as its potential for reinfection and increased pathogenesis in the population groups at higher risk for complications. The main aim of this study was detection and monitoring of wild-type or vaccine VZV strain isolates in the region of Eastern Bohemia and genotypic characterization of these isolates.

Material. A total of 273 clinical samples were obtained from patients exhibiting symptoms of varicella zoster virus (VZV) infection manifested as chickenpox or herpes zoster (HZ) treated in the Faculty Hospital of Charles University, Medical School in Hradec Kralove, Czech Republic.

Methods. Characterization of individual short VZV DNA sequences was performed utilizing restriction fragment length polymorphisms (RFLPs), PCR and sequencing. Single nucleotide polymorphisms (SNP) in open reading frames (ORF) 21, 22 and 50 were used to identify individual VZV strains.

Results. All clinical isolates (97 from varicella, 176 from herpes zoster) were VZV positive wild-type strains. Sequencing analysis showed that 89 isolates were of the European E1 genotype, 180 were of the European E2 genotype and 2 were identified as the Mosaic M1 strain. In addition, for the first time in this region two unusual genotypes were identified, both representing a combination of E1 and M2 strain specific SNPs.

Conclusion. Our prospective VZV genotyping study which is the first to monitor the VZV epidemiological situation in the Czech Republic using such a large set of clinical specimens, has provided valuable epidemiological data and identified two unique VZV recombinants.

\section{INTRODUCTION}

Varicella zoster virus, a member of Herpesviridae, is a highly contagious and neurotropic virus which infects only humans. All herpes viruses have the capacity to induce life-long latency in the infected organisms from which viruses can be reactivated at any time.

VZV is the only human herpetic virus exhibiting an entirely different clinical picture during the primoinfection vs reactivation. The primoinfection - chickenpox is typically a seasonal, predominantly childhood disease with peaks during late winter and early spring. In tropical and subtropical regions however, the peak incidence of chickenpox is during adolescence ${ }^{1}$. There is no seasonality of the disease in tropical countries. The genome of VZV consists of $125-\mathrm{kp}$ of double - stranded DNA and is extremely stable ${ }^{2}$. The variability between individual strains is only $\sim 0.1 \%$ and is manifested as single nucleotide polymorphisms (SNP) $\left(\right.$ ref. $\left.^{3}\right)$.
In the Czech Republic the incidence of chickenpox has been oscillating around 35-40,000 cases/year during the last decade. There were three incidence peaks - in the years 1998, 2004 and 2007, when the incidence reached 50,000 cases/year. The cases occur mostly during the period from January to June with a peak in May (source Epidat, available from: www.szu.cz). After the primoinfection the virus establishes a latency in the sensory ganglia and can be reactivated as herpes zoster (shingles) by various factors, which are typically able to reduce both local and general resistance, such as a psychosomatic stress, older age or UV exposure, and toxic effects. The data from Epidat from the Czech Republic show an average of 6,000 cases of zoster annually during the last decade. In the Czech Republic as elsewhere women are affected about 1.4 times more often than men and the peak incidence of shingles is around 70 years of age ${ }^{4}$. Despite the availability of an efficient vaccine, VZV remains an important public health concern. 
Utilizing molecular methods, several different wildtype strains of VZV can be distinguished based on the presence of typical SNP combinations ${ }^{5-8}$ (Table 3). The main factors affecting the distribution of the individual VZV strains are both the past and current migration of populations, as well as the climate in various geographic areas $^{1,5,9,10}$. The geographical distribution of different VZV strains is characterized by three main areas with characteristic distribution, which are separated by the Tropics of Cancer and Capricorn ${ }^{6-8}$. Mosaic strains (M) of VZV, which likely originated by recombination and selection pressure from the European (E) and Japanese (J) strains, are more prevalent in subtropical and tropical regions. The European strains are typically found in areas with a moderate climate located on both hemispheres, as well as in Australia ${ }^{7}$. The Japanese strain $\mathbf{J}$ is typical for Japan and some other Asian countries, such as South Korea,
Taiwan or Mongolia. In addition, the RFLP strategy can also distinguish the live-attenuated Oka vaccine strains from wild-type VZV strain $^{6-8}$. In this study, the presence of E1 and E2 genotypes of VZV was resolved in a large cohort of patients reporting to the faculty hospital in the Eastern Bohemia on the basis of SNPs located in ORF 21, 22 and/or ORF 50 (Table 3). In addition, several recent studies have reported the possibility of recombination events occurring between VZV strains ${ }^{8,9}$ and we report identification of 2 unique recombinants in this study.

\section{MATERIAL AND METHODS}

In order to investigate the distribution of VZV strains in the Czech Republic on a larger and statistically more significant scale we performed a thorough genomic analy-

Table 1. Characterization of patient cohorts.

\begin{tabular}{|c|c|c|c|}
\hline & & Varicella & Zoster \\
\hline \multicolumn{2}{|r|}{ Number of cases } & 97 & 176 \\
\hline \multirow{2}{*}{ Gender } & Female & 52 & 104 \\
\hline & Male & 45 & 72 \\
\hline \multirow{2}{*}{ Age (years) } & Female & $\langle 2-13\rangle$ & $<45-91>$ \\
\hline & Male & $\langle 3-25\rangle$ & $<55-81>$ \\
\hline \multirow{2}{*}{ Treatment } & Outpatient & 82 & 153 \\
\hline & Hospitalized & 7 & 23 \\
\hline \multirow{8}{*}{ Complications } & Absces & 2 & 0 \\
\hline & Pneumonia & 1 & 0 \\
\hline & Encefalitis & 3 & 2 \\
\hline & Secundary bacterial infection & 1 & 0 \\
\hline & \begin{tabular}{|l|} 
Thrombocytopenia \\
\end{tabular} & 1 & 0 \\
\hline & Hemorrhagic varicella & 1 & 0 \\
\hline & Otitis & 2 & 0 \\
\hline & Conjuctivitis & 0 & 9 \\
\hline \multirow{15}{*}{ Comorbidity } & Diabetes mellitus I. type & 4 & 0 \\
\hline & Diabetes mellitus II.type & 0 & 9 \\
\hline & Tuberculosis & 0 & 1 \\
\hline & Renal tumor & 0 & 1 \\
\hline & Skin lymfom & 0 & 1 \\
\hline & Renal insufficiency & 0 & 11 \\
\hline & Ovarian karcinom & 0 & 1 \\
\hline & Adenocarcinom & 0 & 1 \\
\hline & Prostate cancer & 0 & 2 \\
\hline & Lymphoid leukemia & 0 & 1 \\
\hline & Liver and renal trasplantation & 0 & 1 \\
\hline & Asthma & 6 & 34 \\
\hline & \begin{tabular}{|l|} 
Arterial hypertensis \\
\end{tabular} & 0 & 57 \\
\hline & Renal polycystosis & 0 & 1 \\
\hline & Surgery of meniscus & 0 & 1 \\
\hline
\end{tabular}


sis of a total of $273 \mathrm{VZV}$ isolates obtained from patients in Kralovehradecky region during the period 2005-2010 (Fig. 1). The clinical specimens were obtained during the eruption stage of disease at the Department of Dermatology or Department of Infectious Diseases of the Faculty Hospital in Hradec Kralove. This study enrolled both outpatients and inpatients (Table 1). None of the patients in the two cohorts were related or knew each other and there was no unifying epidemiological factor among the samples. Within the cohort of chickenpox patients there were 45 males and 52 females aged 2 to 25 years. In the zoster cohort there were 104 female and 72 male patients aged 45 to 91 years (Table 1 ).

A sterile swab was used to scrub the base of the unroofed vesicular lesions. DNA was extracted and purified from clinical samples using MagnaPure (Roche Diagnostics), according to the manufacturer's instructions. PCR-based assays followed by genotyping method were performed as described previously ${ }^{6-8}$.
Table 2. Distribution of wild-type VZV genotypes in analyzed clinical specimens.

\begin{tabular}{|l|r|r|r|c|c|}
\hline & E1 & E2 & M1 & E1-M2 & J \\
\hline Varicella & 35 & 62 & 0 & 0 & 0 \\
\hline Zoster & 59 & 113 & 2 & 2 & 0 \\
\hline Total & 94 & 175 & 2 & 2 & 0 \\
\hline Bgl+ & 0 & 0 & 2 & 2 & 0 \\
\hline Bgl- & 94 & 175 & 0 & 0 & 0 \\
\hline Pst + & 94 & 175 & 2 & 2 & 0 \\
\hline
\end{tabular}

\section{RESULTS AND DISCUSION}

The samples were first subjected to an initial analysis by RFLP assay to detect markers in the ORF 38 and 54, which show restriction patterns characteristic for either the wild-type or Oka vaccination strains when digested by restriction enzymes PstI and BgII (ref. ${ }^{11,12}$ ). All tested specimens were VZV DNA positive. Our analysis showed

Table 3. Analysis of genomic variations from VZV open reading frames 21, 22 and 50 (ref. ${ }^{8}$ ).

\begin{tabular}{|c|c|c|c|c|c|c|c|}
\hline \multirow[b]{2}{*}{ ORF } & \multirow[b]{2}{*}{ POSITION } & \multicolumn{6}{|c|}{ GENOTYPE } \\
\hline & & E1 & E2 & M1 & M2 & E1-M2 & $\begin{array}{c}\text { DUMAS } \\
\text { (E1) }\end{array}$ \\
\hline \multirow[t]{2}{*}{ ORF 21} & 33725 & $\mathrm{~T}$ & $\mathrm{C}$ & $\mathrm{C}$ & $\mathrm{C}$ & $\mathrm{T}$ & $\mathrm{T}$ \\
\hline & 33728 & $\mathrm{~T}$ & $\mathrm{C}$ & $\mathrm{C}$ & $\mathrm{C}$ & $\mathrm{T}$ & $\mathrm{T}$ \\
\hline \multirow[t]{4}{*}{ ORF 22} & 37902 & A & A & A & A & A & A \\
\hline & 38055 & $\mathrm{~T}$ & $\mathrm{~T}$ & $\mathrm{~T}$ & $\mathrm{C}$ & $\mathrm{C}$ & $\mathrm{T}$ \\
\hline & 38081 & A & $\mathrm{A}$ & $\mathrm{C}$ & $\mathrm{C}$ & $\mathrm{C}$ & A \\
\hline & 38177 & G & $\mathrm{G}$ & G & A & A & G \\
\hline ORF 50 & 87841 & $\mathrm{C}$ & $\mathrm{T}$ & $\mathrm{T}$ & $\mathrm{T}$ & $\mathrm{C}$ & $\mathrm{C}$ \\
\hline
\end{tabular}



Fig. 1. Kralovehradecky region is situated in Eastern part of Czech Republic. The region consists of 15 counties, has $4758 \mathrm{~km}^{2}$ and 561136 inhabitants. There are 115 people per $1 \mathrm{~km}^{2}$. The Faculty Hospital is located in the seat of the region - Hradec Kralove. 
a)

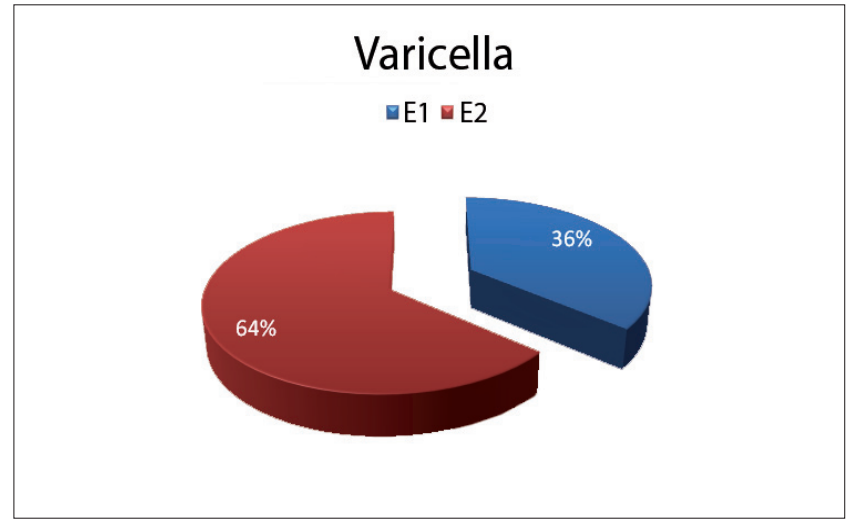

b)

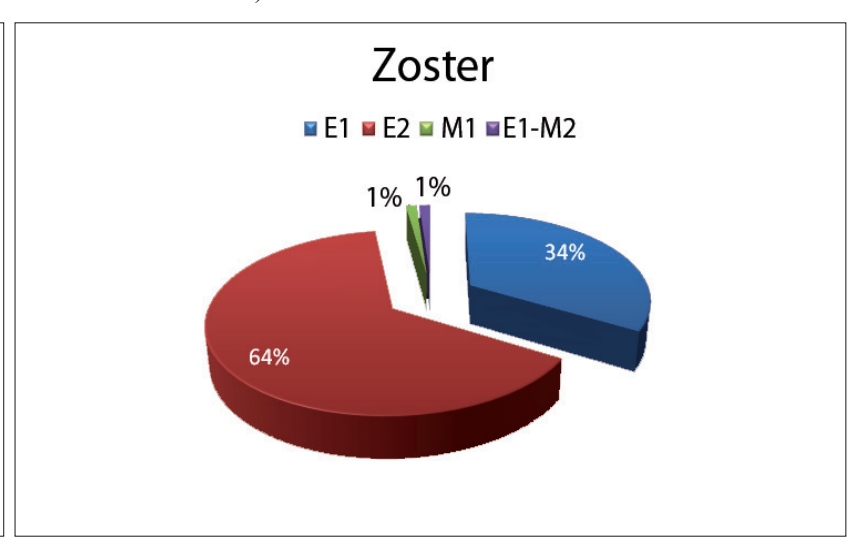

Fig. 2. Prevalence of different genotypes in patients with chickenpox and patients with herpes zoster. A total of 97 VZV isolates from chickenpox (a) and 176 isolates from herpes zoster (b) lesions from Kralovehradecky region were analyzed by RFLP and sequencing. The percentages of prevalence of the individual VZV strains are shown.

that all samples contained only wild-type VZV DNA and none of the isolates contained Oka vaccine strain markers. As a second step aimed at the identification of the individual wild-type VZV strains, genotyping focused on SNPs in ORFs 22,21 and 50 was performed ${ }^{6-8}$. This strategy has been shown to be $100 \%$ specific for distinguishing the wild-type VZV isolates into three clades - $\mathrm{E}, \mathrm{M}$ and $\mathrm{J}$. The correlation of the individual SNP differences in each VZV isolate to the reference strain Dumas (accession number $\mathrm{X} 04370$ ) is shown in (Table 3). In this analysis, four SNPs in the ORF 22 - \#37902, 38055, 38081 and 38177 - are sufficient to identify genotypes E, M1 and M2. Further analysis of ORF21 (positions \#33725 and 33728) and/or ORF50 (SNP \#87841) discriminates between the E1 and E2 genotypes ${ }^{8}$. The analysis of DNA sequences was performed by the DNAStar package (DNASTAR Inc) and ClustalW algorithm was utilized for sequence alignments.

Table 2 and Fig. 2 summarize the results of this analysis. As can be seen, the obtained data identified mostly European strains E1 and E2 among both the chickenpox and zoster isolates, which is not surprising due to the absence of foreign nationals from other geographic areas. In the varicella cohort 35 samples were E1 positive and 62 isolates represented the $\mathrm{E} 2$ clade. In the zoster cohort, 59 and 104 samples tested positive for E1 and E2 clades, respectively. The overall analysis of all patients regardless of manifestation (both varicella and zoster patients together) showed that the E2 clade was dominant in this area with 175 samples (65\%) positive, while 94 samples (35\%) tested positive for E1.

Interestingly, isolates from 2 patients with zoster were positive for the M1 genotype. Their anamnestic data showed that both patients traveled abroad shortly before the appearance of the symptoms - to the Netherlands and Mauritius in the first case, and to Italy, France and Croatia in the second case.

In addition, as a completely new and unexpected finding, samples from two zoster patients (female, 53 years old and male, 60 years old) tested positive for unusual VZV recombinants containing combinations of SNPs characteristic for E1 and M2 clades (Table 3). The first was a 60 year old male patient with renal insufficiency, who presented with zoster in a very unusual location - in the distal third of his calf. This patient had a history of frequent travel to Greece, Turkey, Egypt and Tunisia.

The second patient, a 53 year old female, presented with a recurrent zoster. During the duration of this study she visited our hospital with new zoster manifestations five times - in June 2009, November 2009, February 2010, April 2010 and October 2010. The patient had a history of repeated travel to Egypt. This patient has been followed for allergic rhinoconjunctivitis and moderate bronchial asthma for several years. Several other disorders were confirmed in her personal case history, e.g. degenerative involvement of intervertebral discs L1-S1 (lumbal vertebrogenic algesic syndrome) was diagnosed about 2 weeks before one clinical manifestation of herpes zoster.

Clearly, an additional genotypic analysis of isolates from these two patients will be beneficial to understand the potential recombination process.

In 22 cases out of 273 , the patients developed or already presented with some VZV complications. The list of individual complications and comorbidities is shown in (Table 1). Some of the patients had more than one comorbidity and within these combined comorbidities asthma, arterial hypertension and renal insufficiency were often present. However, there was no clear correlation between the distribution of individual E1 or E2 wild-type VZV strains and presence of complications and/or comorbidites.

\section{CONCLUSION}

Genotypic analysis represents an important epidemiologic tool for typing of a variety of herpetic viruses ${ }^{8,10}$. These studies generate data useful for epidemiological surveillance and in future they may lead to establishing links between sequence variations and virus pathogenicity ${ }^{13}$ or drug resistance, similarly to the already proven cor- 
relations for other viruses, such as HIV. More new studies analyzing sequence variants and genomic markers among VZV isolates are important keys for information about the pathogenic potential of individual VZV strains. Genotypic studies enable better understanding of infection epidemics and studies on larger cohorts can provide additional insight into both VZV evolution and mechanisms of VZV persistence. This is the first individual prospective study from the Czech Republic.

In summary, the data presented here demonstrate the prevalence of circulating European E2 clade (175 cases) as well as E1 (94 cases) and M1 clades (2 cases) in the Czech Republic. This correlation is in agreement with previously published summary by Schmidt-Chanasit and Sauerbrei, 2011 (ref. $^{14}$ ) showing prevalence rates of E1 to E2 strains in cohorts of varying size from 4 European countries: Czech Republic ( 7 isolates of E1/8 isolates of E2),Finland (10 isolates of E1/18 isolates of E2), Germany (166 isolates of E1/209 isolates of E2) and Iceland ( 1 isolate of E1/15 isolates of E2). Interestingly, when all available data from 19 European countries were pooled in the summary by Schmidt-Chanasit et al., 2009 (ref. ${ }^{15}$ ) on average the most prevalent clade in Europe was E1 (368 isolates of E1/275 isolates of E2). Some isolates of M1 clade were reported from France ( 2 cases), Germany ( 59 cases) and Spain ( 9 cases) while M2 strains were found in France (1) Germany (3) Iceland (1). Only in Germany there were 5 cases identified as $\mathrm{J}$ strain virus, which could be due to a relatively large Asian immigrant community in this country. Therefore our data on a large cohort confirm the findings of Schmid-Chanasit and Sauerbrei, 2011 (ref. ${ }^{14}$ ) of the majority of E2 clade VZV strains in both varicella and zoster patients from this geographic area. In addition, we identified two M1 VZV strains which we can only speculate were imported due to the rich travel history of the two patients.

In our study, we have detected for a first time an unusual strain, characterized by a genotypic combination of E1 and M2 (Table 2, Table 3) in patients with either atypically localized or recurrent zoster. Both patients were Caucasian and had an extensive travel history to subtropical and tropical countries.

In our entire set of clinical specimens we found no VZV Oka vaccine strain isolate. Two different live attenuated varicella vaccines are available in the Czech Republic. Our data therefore show that so far in our cohort of patients there has been no recombination between the wt and vaccine virus, nor was the vaccine virus a causative agent of the VZV disease. The future goal of our work will be achieved by vaccine related surveillance measures, such as monitoring the vaccine coverage, vaccine safety and vaccine effectiveness. Another aspect of the VZV genotyping will be to moniter the potential appearance of highly modified varicella in vaccinated persons. The monitoring and interpretation of trends in herpes zoster and implementing the obtained data in the analysis of prediction of hospitalization and treatment may then help to reduce costs associated with the VZV infection.

Breakthrough infection is well known as possible result from the lack of cross-protectivity of Oka strain against other geographically segregated strains of VZV, including specific European strains. In Europe, these European strains predominate and the efficacy of the Oka strain against these genotypes is being examined in European studies $^{16}$.

Taken together the data from this prospective study in the Czech Republic provide a baseline for estimating the burden of VZV infections and also support the inclusion of VZV vaccination in the immunization program in this country.

\section{ACKNOWLEDGEMENT}

This work was supported by grant P304/10/1161 from the Grant Agency of Czech Republic.

The authors do not have any conflict of interest.

\section{REFERENCES}

1. Quinlivan M, Hawrami K, Barrett-Muir W, Aaby P, Arvin A, Chow VT, John TJ, Matondo P, Peiris M, Poulsen A, Siqueira M, Takahashi M, Talukder Y, Yamanishi K, Leedham-Green M, Scott FT, Thomas SL, Breuer J. The molecular epidemiology of varicella-zoster virus: evidence for geographic segregation. J Infect Dis 2002;186;888-94.

2. Davison AJ, Scott JE.The complete DNA sequence of varicellazoster virus. J Gen Virol 1986; 67;1759-1816.

3. Gomi Y, Sunamachi H, Mori Y, Nagaike K, Takahashi M, Yamanishi K. Comparison of the complete DNA sequences of the Oka varicella vaccine and its parental virus. J Virol 2002;76; 11447-59.

4. Smetana J, Bostikova V, Salavec M, Chlibek R, Splino M, Plisek S, Prasil P, Kosina P, Bostik P. Herpes zoster in Czech Republic epidemiology and clinical symtoms. EMI 2010;3:138-46 (in Czech).

5. Barrett-Muir W, Scott FT, Aaby P, John J, Matondo P, Chaudhry QL, Siqueira M, Poulsen A, Yaminishi K, Breuer J. Genetic variation of varicella-zoster virus: evidence for geographical separation of strains. J Med Virol 2003;70;S42-7.

6. Loparev VN, Gonzalez A, Deleon-Carnes M, Tipples G, Fickenscher H, Torfason EG, Schmid DS. Global identification of three major genotypes of varicella-zoster virus: longitudinal clustering and strategies for genotyping. J Virol 2004;78;8349-58.

7. Loparev VN, Rubtcova EN, Bostik V, Govil D, Birch CJ, Druce JD, Schmid DS, Croxson MC. Identification of five major and two minor genotypes of VZV strains: a practical two-amplicon approach used to genotype clinical isolates in Australia and New Zealand. J Virol 2007;81;12758-65.

8. Loparev VN, Rubtcova EN, Bostik V, Tzaneva V, Sauerbrei A, Robo A, Sattler-Dornbacher E, Hanovcova I, Stepanova V, Splino M, Eremin V, Koskiniemi M, Vankova OE, Schmid DS. Distribution of VZV wild-type genotypes in northern and southern Europe: evidence for high conservation of circulating genotypes. Virology 2009;383;216-25.

9. Norberg P, Bergström T, Rekabdar E, Lindh M, Liljeqvist JA. Phylogenetic analysis of clinical herpes simplex virus type 1 isolates identified three genetic groups and recombinant viruses. J Virol 2004; 78; 10755-64.

10. Tipples GA et al. Tipples GA, Safronetz D, Gray MA real-time PCR assay for the detection of varicella-zoster virus DNA and differentiation of vaccine, wild-type and control strains. J Virol Methods 2003;113;113-16.

11. LaRussa P, Lungu O, Hardy I, Gershon A, Steinberg SP, Silverstein S. Restriction fragment length polymorphism of polymerase chain reaction products from vaccine and wild-type varicella-zoster virus isolates. J Virol 1992;66;1016-20. 
12. LaRussa P, Steinberg S, Arvin A, Dwyer D, Burgess M, Menegus M, Rekrut K, Yamanishi K, Gershon A. Polymerase chain reaction and restriction fragment length polymorphism analysis of varicellazoster virus isolates from the United States and other parts of the world. J Infect Dis 1998;178;S1:S64-6.

13. Breuer J, Schmid SD, Norberg P. A proposal for a common nomenclature for viral clades that form the species varicella-zoster virus: summary of VZV Nomenclature Meeting 2008, Barts and the London School of Medicine and Dentistry, 24-25 July, 2008. J Gen Virol 2010;91;821-8.
14. Schmidt-Chanasit J, Sauerbrei A. Evolution and world-wide distribution of varicella-zoster virus clades. Infection, Genetics and Evolution 2011;11(1);1-10.

15. Schmidt-Chanasit J, Stürmer M, Hahn A, Schäd SG, Gross G, Ulrich RG, Heckel G, Doerr HW. Novel approach to differentiate subclades of varicella-zoster virus genotypes E1 and E2 in Germany. Virus Research 2009;145;347-49.

16. Sengupta N, Booy R, Schmitt HJ, Peltola H, Van-damme P, Schumacher RF, Campins M, Rodrigo C, Heikkinen T, Seward J, Jumaan A, Finn A, Olcen P, Thiry N, Weil-Olivier C, Breuer J.Varicella vaccination in Europe: are we ready for a universal childhood programme? Eur J Pediatr 2008;167;47-55. 